\title{
Interfacial Areas and Gas Hold-ups at Elevated Pressures in a Mechanically Agitated Gas-Liquid Reactor
}

\author{
Martin Oyevaar, Ad Zijl and Roel Westerterp*
}

\begin{abstract}
Interfacial areas and gas hold-ups were determined at pressures of up to $1.7 \mathrm{MPa}$ in a glass vessel, $88 \mathrm{~mm}$ in diameter and of standard geometry. Superficial gas velocities between 0.25 and $2.0 \mathrm{~cm} / \mathrm{s}$ were used and the stirring speed varied between 4 and $30 \mathrm{rps}$. The interfacial areas were determined by the chemical method, using the model reaction between $\mathrm{CO}_{2}$ and aqueous diethanolamine (DEA). Hold-ups were determined by observation of differences in height. In contrast to literature indications, the gas hold-up was found to be independent of reactor pressure. This is also true for the interfacial area.
\end{abstract}

\section{Introduction}

Gas-liquid contacting is an operation often used in industrial processing. The gas-liquid mass transfer can represent a major limitation on the rate of absorption or desorption. The mass transfer coefficient, interfacial area and gas hold-up are largely determined by the choice of reactor type. In practice, they can be varied only within certain limits by changing flow rates, reactor geometry or agitation characteristics. The gas-liquid mass transfer rate can be improved by increasing the driving force for mass transfer. This can be achieved by increasing partial pressure of the component, which is being absorbed, or the total pressure in the reactor.

Only in the past two decades, research on the influence of operating pressure on mass transfer characteristics in different types of reactor has been reported although it has long been known that some high pressure gas-liquid reactors operate at extremely large gas hold-ups, see Tarmy et al. [1]. The scarce results, reported so far, for different reactors and gas-liquid systems are contradictory regarding the effect of operating pressure on interfacial area and gas hold-up. Changes of up to $200 \%$ in the gas hold-up were reported by Pijls et al. [2], Idogawa et al. [3, 4] and Tarmy et al. [1] in two- and three-phase bubble columns operating at up to $15 \mathrm{MPa}$. On the other hand, gas holdup measurements reported by Vafopoulos et al. [5], Deckwer et al. [6] and Kölbel et al. [7] in bubble columns at up to $2.0 \mathrm{MPa}$ show no effect of the reactor pressure. The same contradictions were observed in the case of mechanically agitated reactors, where Vafopoulos et al. [5] and Albal et al. [8, 9] found no influence of pressure on the volumetric liquid phase mass transfer coefficient or the interfacial area, while Sridhar and Potter [10, 11] report increases in interfacial area and gas hold-up of as much as $75 \%$ for a pressure increase from 0.1 to $1 \mathrm{MPa}$. The above mentioned contradictory results can lead to considerable miscalculations, whichever correlation is adopted.

The object of the present investigation is to contribute to the understanding of the influence of operating pressure on mass trans-

* Ir. M.H. Oyevaar, Ir. A.D. Ziji (present address: ICI Holland), and Prof. Dr. Ir. K.R. Westerterp, University of Twente, Faculty of Chemical Engineering, Chemical Reaction Engineering Laboratories, PO Box 217 , NL-7500 AE Enschede. fer parameters in several types of reactor. This report is restricted to the mechanically agitated gas-liquid reactor and includes the authors' first determinations of interfacial areas and gas hold-ups in a small reactor operating at pressures of up to $1.7 \mathrm{MPa}$. The interfacial areas were determined by the chemical method using the model reaction between $\mathrm{CO}_{2}$ and aqueous diethanolamine (DEA). The gas hold-ups were obtained from the difference between gassed and non-gassed dispersion heights.

\section{Literature Survey}

Some twenty papers have been published which either deal with or mention the influence of operating pressure in gas-liquid systems. This section gives the main conclusions and discusses in more detail some interesting studies on the influence of pressure on the interfacial area and gas hold-up. A comprehensive review will be presented in a future publication. With respect to terminology, gas flow rates are always based on volumetric rates; thus, at constant volumetric flow rates $\phi_{v}$, mass flow rates $\phi_{\mathrm{m}}$ increase with pressure, on account of increasing density. Therefore, superficial gas velocities refer to the volumetric gas flow rates per unit cross-sectional area of the empty reactor.

The literature results can be classified into those concerned with the influence of operating pressure on:

1) formation and coalescence behaviour of single bubbles in gasliquid systems.

2) gas and liquid phase mass transfer coefficients in gas-liquid reactors.

3) volumetric liquid phase mass transfer coefficient, interfacial area and gas hold-up in gas-liquid reactors.

Good agreement exists between the results of several workers on the influence of pressure on bubble formation at single orifices. An increase in the system pressure at a constant volumetric gas flow rate results in a decrease of the initial bubble diameter and an increase of bubble frequency at the gas inlet orifice, see e.g. LaNauze and Harris [12] and Idogawa et al. [13].

Several investigators concluded that the operating pressure does not affect the liquid phase mass transfer coefficient $k_{\mathrm{L}}$ in flat- 
surface reactors, mechanically agitated reactors and bubble columns, see e.g. Albal et al. [8,9] and Vafopoulos et al. [5]. This appears obvious, since pressure does not exert any significant influence on surface tension, viscosity or density of the liquid.

In contrast, the mass transfer coefficient in the gas phase is affected by pressure since diffusivity is inversely proportional to the total system pressure; in the case of ideal gases, the product of density and diffusivity of the gas phase remains constant. Versteeg et al. [14] report for a flat-surface reactor that the gas phase mass transfer coefficient is inversely proportional to the square root of total pressure, which is in accordance with the penetration theory.

Conflicting views prevail on the influence of operating pressure on the volumetric liquid phase mass transfer coefficient $k_{\mathrm{L}} a$ in surface-aerated agitated reactors. Teramoto et al. [15] and Albal et al. $[8,9]$ reported no effect of pressures of up to $9.5 \mathrm{MPa}$ in different gas-liquid systems with water, ethanol, $p$-xylene and paraffin wax as liquids. Deimling [16] measured a significant increase in $k_{\mathrm{L}} a$ for three different Fischer-Tropsch type liquids, at pressures ranging from 1 to $5 \mathrm{MPa}$. In all three publications, no influence of pressure on $k_{\mathrm{L}}$ in reactors with flat surfaces was observed. Thus, these three studies also lead to conflicting conclusions with respect to the interfacial area.

The same contradiction is found with regard to the influence of operating pressure on interfacial areas and gas hold-ups in mechanically agitated gas-liquid reactors. Vafopoulos et al. [5] found no influence of pressures between 0.1 and $1 \mathrm{MPa}$ in airwater systems while, within the same pressure range, Sridhar and Potter $[10,11]$ observed an increase of as much as $75 \%$ in the interfacial areas and gas hold-ups for the system oxygencyclohexane. Sridhar and Potter $[10,11]$ attributed the increase of the mass transfer parameters to the increase of kinetic energy of the gas inlet flow with pressure. In order to correlate their results, they modified the equations of Calderbank [17] by multiplying them by a factor $\left(E_{\mathrm{t}} / P_{\mathrm{g}}\right)\left(\varrho_{\mathrm{g}} / \varrho_{\mathrm{air}}\right)^{0.16}$, where the first term represents the ratio of the total kinetic and mechanical energy, supplied to the dispersion, to the power input by agitation only. A second correction for gas density had to be applied, so that it was not possible to correct for the influence of pressure solely by the increase of kinetic energy in the gas flow.

This was confirmed for a bubble column by Pijls et al. [2], who found a twofold increase of the gas hold-up for a pressure increase of up to $2 \mathrm{MPa}$. They used an air-water system with different sparger rings and concluded that neither an increase in kinetic energy nor in momentum can explain the increase in the gas holdup. For different gas-liquid systems, Idogawa et al. [4] also found an increase in the gas hold-up with increasing pressures, up to 15 $\mathrm{MPa}$. They also observed a decrease in the mean bubble diameter. Their findings imply quadrupled interfacial areas for a pressure increase of 0.1 to $5 \mathrm{MPa}$. The results reported in a threephase bubble column by Tarmy et al. [1] show a twofold increase in the gas hold-up with an increase in pressure from 0.12 to 0.62 MPa. In contrast to these three reports, Vafopoulos et al. [5], Kölbel et al. [7] and Deckwer et al. [6] found no evidence of pressure influence on gas hold-ups and bubble diameters in two- and three phase bubble columns.
The above review points to a consensus regarding the effect of pressure on bubble formation and mass transfer coefficient in the gas phase. It is also confirmed that the mass transfer coefficient in the liquid phase is independent of operating pressure. However, there appears to be a great deal of confusion regarding the effect of operating pressure in gas-liquid reactors on the mass transfer parameters such as the interfacial area and gas hold-up. A systematic investigation of these effects in different gas-liquid reactors appears justified.

\section{Chemical Method for the Determination of Interfacial Areas}

The chemical method was employed to determine the interfacial areas. The method is based on the theory of chemically enhanced absorption of a gas phase component $\mathrm{A}$ into a liquid where an irreversible reaction occurs with a liquid phase component $B$. By a careful choice of physico-chemical conditions, it is possible to determine $a, k_{\mathrm{L}} a$ or $k_{\mathrm{g}} a$, see Sharma and Danckwerts [18] and Westerterp et al. [19].

The general equation for molar flux $J_{\mathrm{A}}$ of a component A from the gas into the liquid phase is ${ }^{1)}$

$J_{\mathrm{A}}=\frac{k_{\mathrm{L}} E_{\mathrm{A}}\left(m \bar{c}_{\mathrm{A}, \mathrm{G}}-\bar{c}_{\mathrm{A}, \mathrm{L}}\right)}{1+\left(m k_{\mathrm{L}} E_{\mathrm{A}} / k_{\mathrm{G}}\right)}$,

where $E_{\mathrm{A}}$ is the enhancement factor which accounts for the effect of chemical reaction on the rate of absorption.

If the reaction is sufficiently fast to consume all $\mathrm{A}$ absorbed in the film or if the liquid bulk volume is much larger than the film volume, the bulk concentration of component $A$ in the liquid phase, $\bar{c}_{\mathrm{A}, \mathrm{L}}$, is nil. In most gas-liquid reactors and systems with moderate reaction rates and low gas solubilities, no gas phase mass transfer limitation occurs and Eq. (1) becomes

$J_{\mathrm{A}}=k_{\mathrm{L}} m \bar{c}_{\mathrm{A}, \mathrm{G}} E_{\mathrm{A}}$

provided that

$\mathrm{Al}=\left(\left(1-\varepsilon_{\mathrm{G}}\right) k_{\mathrm{L}}\right) /\left(a D_{\mathrm{A}}\right)>>1$ and

$k_{\mathrm{G}}>>m k_{\mathrm{L}} E_{\mathrm{A}}$

Using the Danckwerts penetration theory, the enhancement factor can be calculated from

$E_{\mathrm{A}}=\sqrt{1+\mathrm{Ha}^{2}}$

in which the Hatta number, $\mathrm{Ha}$, is given by

$\mathrm{Ha}=\frac{\sqrt{(2 /(n+1)) k_{\mathrm{n}, \mathrm{p}}\left(\bar{c}_{\mathrm{B}, \mathrm{L}}\right)^{p}\left(m \bar{c}_{\mathrm{A}, \mathrm{G}}\right)^{(n-1)} D_{\mathrm{A}}}}{k_{\mathrm{L}}}$.

1) List of symbols at the end of the paper. 
With no depletion of the liquid component $B$ in the film and a first order reaction with respect to the absorbing component $\mathrm{A}$, the pseudo-first order Hatta number becomes

$\mathrm{Ha}=\frac{\sqrt{k_{1, \mathrm{p}}\left(\bar{c}_{\mathrm{B}, \mathrm{L}}\right)^{p} D_{\mathrm{A}}}}{k_{\mathrm{L}}}$

provided that

$\mathrm{Ha}<<E_{\mathrm{A}, \infty}$, where

$E_{\mathrm{A}, \infty}=\sqrt{D_{\mathrm{A}} / \bar{D}_{\mathrm{B}}}+\sqrt{D_{\mathrm{B}} / D_{\mathrm{A}}}\left(\bar{c}_{\mathrm{B}, \mathrm{L}} /\left(m \bar{c}_{\mathrm{A}, \mathrm{G}} \nu_{\mathrm{B}}\right)\right)$.

$E_{\mathrm{A}, \infty}$ is the enhancement factor for instantaneous reaction. According to Eq. (5), $E_{\mathrm{A}}$ becomes unity for $\mathrm{Ha}<0.5$ and equal to $\mathrm{Ha}$ for $\mathrm{Ha}>2$

$\mathrm{Ha}<0.5: E_{\mathrm{A}}=1$ and $J_{\mathrm{A}}=k_{\mathrm{L}} m \bar{c}_{\mathrm{A}, \mathrm{G}}$,

$\mathrm{Ha}>2: E_{\mathrm{A}}=\mathrm{Ha}$ and $J_{\mathrm{A}}=m \bar{c}_{\mathrm{A}, \mathrm{G}} \sqrt{k_{1, \mathrm{p}}\left(\bar{c}_{\mathrm{B}, \mathrm{L}}\right)^{p} D_{\mathrm{A}}}$.

Since $\phi_{\mathrm{A}}=J_{\mathrm{A}} a V_{\mathrm{R}}$, application of this theory to chemical reactors makes it possible to determine the volumetric liquid-phase mass transfer coefficients and interfacial areas from absorption rate measurement. This requires the knowledge of the physicochemical parameters and of the driving force, in order to verify the relevant criteria and to make correct evaluations.

The reaction between oxygen and aqueous sodium sulphite solutions, catalyzed by cobaltous ions $\mathrm{Co}^{2+}$, has been used extensively. However, there is still some controversy regarding the reaction kinetics and especially the order of reaction with respect to oxygen. This is probably the result of the reaction's sensitivity towards the impurities in water, the catalyst and the sulphite salt, see Linek and Vacek [20]. The main advantage of this reaction is the possibility of varying the rate constant over a wide range by changing the $\mathrm{Co}^{2+}$ catalyst concentration. However, the reaction is restricted to aqueous solutions and, furthermore, the noncoalescing behaviour of this ionic system also limits its use, see Bartos and Satterfield [21].

The reaction between $\mathrm{CO}_{2}$ and aqueous amine solutions was first introduced by Danckwerts and Sharma [22]. Later, Sridharan and Sharma [23] showed that the reaction between $\mathrm{CO}_{2}$ and amines in organic and viscous solutions can also be employed for this purpose. The rate of reaction can be varied by choosing different amines. In recent years, amines have been used to determine mass transfer parameters in different reactors, see e.g. Metha and Sharma [24], Midoux et al. [25], Versteeg [26] and Bartos and Satterfield [21]. The advantages of reactions between $\mathrm{CO}_{2}$ and amines are:

1) the possibility of setting up different regimes of the chemical method by selecting different amines and different concentrations.

2) the possibility of employing aqueous, organic and viscous solutions.

3) the certainty of the reaction order with respect to $\mathrm{CO}_{2}$ being unity.
The main disadvantage is the rather high solubility of $\mathrm{CO}_{2} \mathrm{com}-$ pared to those of other gases: this generally results in high $\mathrm{CO}_{2}$ conversions, making the evaluation of the mass transfer parameters sensitive to the chosen gas-phase mixing model.

\section{Experimental}

\subsection{The Chemical System}

Blauwhoff et al. [27] reviewed the available data on the kinetics of primary (MEA), secondary (DEA, DIPA) and tertiary (TEA, MDEA) alkanolamine solutions in water and provided additional data for DEA, DIPA, TEA and MDEA at $298 \mathrm{~K}$. From their results, it can be concluded that aqueous solutions of diethanolamine (DEA) at $298 \mathrm{~K}$ fulfil the criteria for the chemical method to measure interfacial areas in a mechanically agitated gas-liquid reactor.

Commercial grade aqueous 80 vol-\% DEA solutions with a purity of $>98 \%$ and supplied by BASF were used in the absorption experiments. The reaction rates of this amine were determined and compared with the results of Blauwhoff et al. [27] and Versteeg and van Swaaij [28]. An excellent agreement between reaction rates at $298 \mathrm{~K}$ was found for DEA concentrations between 0.5 and $2.0 \mathrm{~mol} / \mathrm{l}$. The kinetic experiments were carried out in stirred vessels with a smooth gas-liquid interface. The experimental set-up was identical to that of Blauwhoff et al. [27]; in the present experiments, pressure decrease was monitored by a pressure transducer connected to a microcomputer which calculated the absorption rate constant $m \sqrt{k}_{1, \mathrm{p}}\left(\bar{c}_{\mathrm{B}, \mathrm{L}}\right)^{p} D_{\mathrm{A}}$ directly, using Eq. (11). The pseudo-first order overall reaction rate constant $k_{\mathrm{ov}}=k_{1, \mathrm{p}}\left(\bar{c}_{\mathrm{B}, \mathrm{L}}\right)^{p}$ can be evaluated from this constant.

The overall rate constants were determined separately for the first twenty fresh or regenerated batches of DEA solutions as used in own absorption experiments: no significant influence of impurities or degradation products was detected.- For subsequent batches, $k_{\text {ov }}$ was not determined any more. Nor is the overall rate constant influenced by the $\mathrm{CO}_{2}$-load in the liquid. This indicates that the deprotonation of the " $z$ witterion" is not influenced by the hydroxyl ion and the absorption rate of $\mathrm{CO}_{2}$ is not affected by the bicarbonate formation reaction, see Blauwhoff et al. [27].

Eq. (11) can be applied without the knowledge of the exact values of the parameters $m, k_{1, \mathrm{p}}, \bar{c}_{\mathrm{B}, \mathrm{L}}, p$ and $D_{\mathrm{A}}$ provided that it is certain that $E_{\mathrm{A}}=\mathrm{Ha}$. In this case, the value of the absorption rate constant, as directly evaluated from a kinetic experiment, can be used. This eliminates the uncertainties of calculation, estimation and measurement of separate parameters.

About 70 kinetic experiments were performed in order to find an empirical correlation between the absorption rate constant $m \sqrt{k_{1, \mathrm{p}}\left(\bar{c}_{\mathrm{DEA}, \mathrm{L}}\right)^{p} D_{\mathrm{CO}_{2}}}$ and the free DEA concentration in the range between 0.2 and $2.0 \mathrm{~mol} / \mathrm{kg}$ at $298 \mathrm{~K}$. The correlation is given in Table 1 together with experimental correlations between the solubility $m$, viscosity $\mu_{\mathrm{L}}$, density $\varrho_{\mathrm{L}}$ and DEA concentration. With a value of $k_{\mathrm{L}}$ between 1 and $4 \times 10^{-4} \mathrm{~m} / \mathrm{s}$, conditions of $\mathrm{Ha}>2$ and $<<\mathrm{E}_{\mathrm{A}}$ can be chosen. 
Table 1. Data for the DEA-Water System at $298 \mathrm{~K}$.

$$
\begin{aligned}
& m \sqrt{k_{1, \mathrm{p}}\left(\overline{\mathrm{c}}_{\mathrm{DEA}, \mathrm{L}}\right)^{p} D_{\mathrm{CO}_{2}}}=9.3835 \times 10^{-4}[\mathrm{DEA}]^{0.380}-2.6101 \times 10^{-4} \\
& m=0.791-0.044[\mathrm{DEA}]^{\prime} \\
& \varrho_{\mathrm{l} .}=0.9958+1.555 \times 10^{-2}[\mathrm{DEA}]-1.1410 \times 10^{-3}[\mathrm{DEA}]^{2} \\
& \mu_{\mathrm{I} .}=\exp \left(-0.1135+2.5718 \times 10^{-1}[\mathrm{DEA}]+4.6937 \times 10^{-2}[\mathrm{DEA}]^{2}\right)
\end{aligned}
$$

[DEA] in $\mathrm{mol} / \mathrm{kg}$ and $[\mathrm{DEA}]^{\prime}$ in $\mathrm{mol} / 1$.

Possible reversibility of the relevant reactions was not taken into account. Actually, amines do react reversibly with $\mathrm{CO}_{2}$. Versteeg et al. [29] showed that, in the case of large deviations from irreversibility, the application of the above equations to kinetic and absorption experiments can result in considerable errors. Using their numerical model, the authors checked this for different $\mathrm{CO}_{2}$ partial pressures, DEA concentrations and conversions. It was concluded that no serious deviations from irreversibility occurred in own kinetic and absorption measurements.

\subsection{Experimental Set-up}

The absorption experiments were performed in a mechanically agitated reactor, see Fig. 1, made of glass and operated continu- ously with respect to the gas and the liquid phase. The reactor can be operated at pressures of up to $2.0 \mathrm{MPa}$ and is thermostatically controlled at $298 \mathrm{~K}$. It has a diameter $T=8.8 \mathrm{~cm}$ and is equipped with a standard six-bladed disc turbine with a diameter of $D_{\mathrm{i}} / T$ $=0.4$, installed at a height of $h / T=0.33$ above the flat bottom plate. The reactor contains four baffles $W / T=0.1$ wide. The dispersion level is maintained at a height of $H / T=1$ by using an overflow vessel. A gas mixture of $\mathrm{CO}_{2}$ and $\mathrm{N}_{2}$ is introduced into the reactor via a sparger located centrally below the impeller. The sparger is either a sintered plate of $d_{\mathrm{i}}=1.0 \mathrm{~cm}$ and $\bar{d}_{\mathrm{p}}=30 \mu \mathrm{m}$ or a single orifice of $d_{\mathrm{i}}=3.0 \mathrm{~mm}$.

Nitrogen and carbon dioxide are supplied via four mass flow controllers keeping the inlet gas flow rate and gas composition constant. Applied flow rates ranged for $\mathrm{N}_{2}$ from 0 to $9 \mathrm{~m}_{\mathrm{N}}^{3} / \mathrm{h}$ and for $\mathrm{CO}_{2}$ from 0 to $0.3 \mathrm{~m}_{\mathrm{N}}^{3} / \mathrm{h}$. Reactor pressure is controlled in the outlet gas flow by a back pressure regulator. The $\mathrm{CO}_{2}$-concentrations in the gas in- and outflow are monitored continuously by a gas chromatograph controlled with an integrator.

Fresh or regenerated DEA solutions were fed from a storage vessel with a volume of $V_{\mathrm{L}}=60 \mathrm{l}$ into the reactor by a high pressure diaphragm pump with a capacity of $35 \mathrm{l} / \mathrm{h}$. The liquid from the reactor flows via the overflow vessel into a liquid buffer vessel with a volume of $V_{\mathrm{I}}=28 \mathrm{l}$. When the buffer vessel is filled up completely, the expcriment is terminated and the buffer empticd

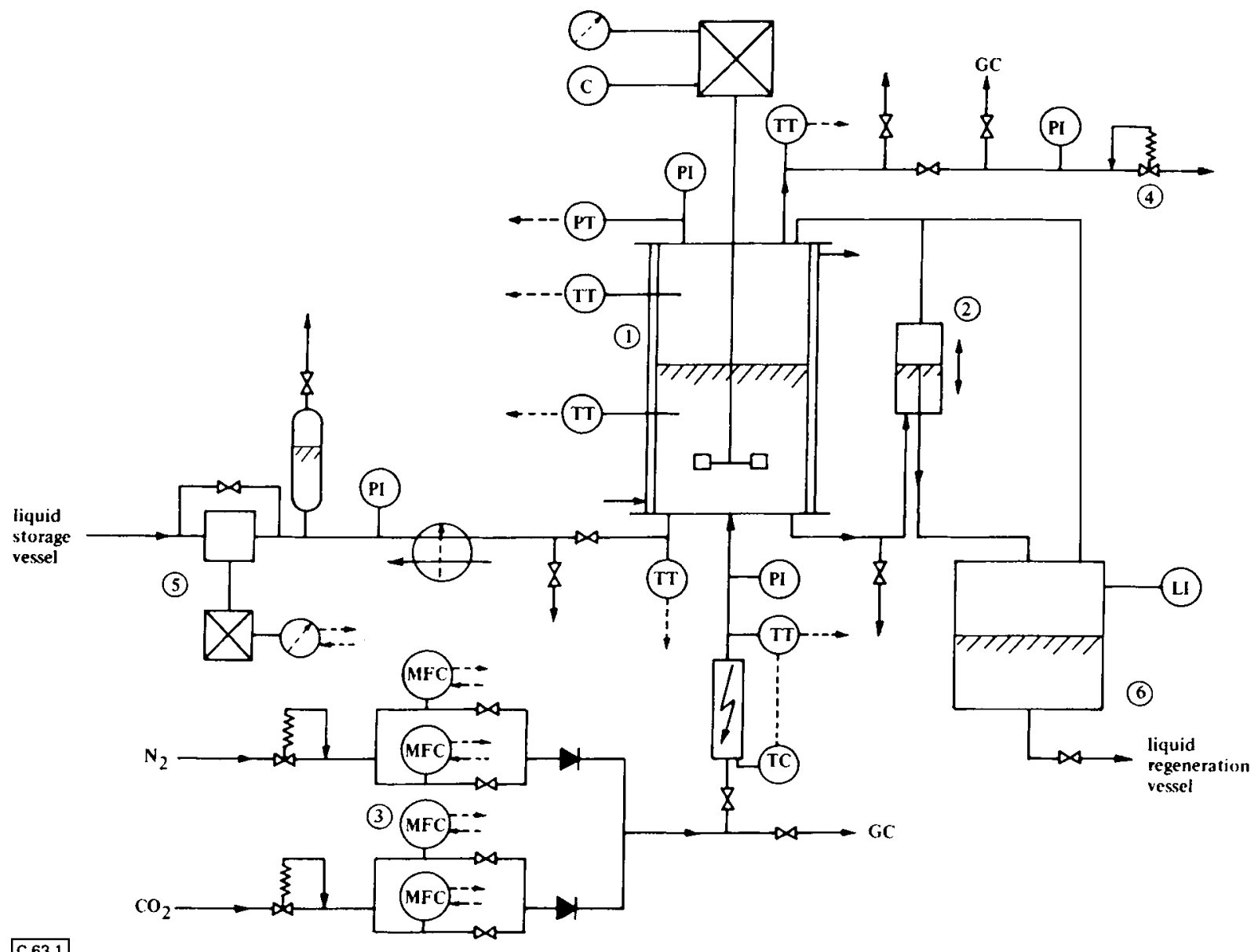

Fig. 1. Experimental set-up. $/$ reactor, 2 overflow vessel, 3 mass flow controllers, 4 back pressure, 5 liquid pump, 6 liquid buffer vessel. 
into the regeneration vessel. This vessel has a volume of $V_{\mathrm{L}}=$ 601 ; therein $\mathrm{CO}_{2}$ is continuously stripped from the solution with nitrogen at temperatures between 350 and $370 \mathrm{~K}$. Regenerated solutions are recycled to the storage vessel and used for new absorption experiments.

The stirring speed can be varied between 0 and 35 rps and is monitored by a tachometer. The liquid feed is thermostated at $298 \mathrm{~K}$, the temperature of the gas feed is kept at $298 \mathrm{~K}$ via an electric heating coil. Reactor pressure and temperature, in- and outlet temperatures and the set points of mass flow controllers and of the pump are continuously monitored by a microcomputer which calculates the flow rates and superficial gas velocity and displays the process conditions.

The set points can be adjusted automatically by the microcomputer. Other process parameters such as the stirring speed, the DEA and the $\mathrm{CO}_{2}$ concentrations in the liquid feed and the $\mathrm{CO}_{2}$ concentrations in the gas flows are fed manually to the computer. After an experiment, all data are stored in data files to be processed later by data manipulation programs.

\subsection{The Experimental Procedure}

Before each absorption experiment, the desired reactor pressure, superficial gas velocity, $\mathrm{CO}_{2}$ fraction in the gas feed and the estimated DEA and $\mathrm{CO}_{2}$ concentrations in the liquid feed are fed into the computer which then calulates the set points for mass flow controllers and liquid pump. The liquid flow rate is adjusted on the basis of a maximum permissible DEA conversion of $20 \%$ if all $\mathrm{CO}_{2}$ is absorbed from the gas phase.

The DEA concentrations vary between 0.8 and $1.1 \mathrm{~mol} / \mathrm{kg}$. For a value of $k_{\mathrm{L}}=2 \times 10^{-4} \mathrm{~m} / \mathrm{s}$, this results in Hatta numbers of around 4, see Eq. (7). The $\mathrm{CO}_{2}$ fraction in the gas feed ranges from 1 to $2 \%$. For a value of $D_{\mathrm{B}} / D_{\mathrm{A}}=0.5$, this results at $298 \mathrm{~K}$ in values of $E_{\mathrm{A}, \infty}>30$ for all pressures.

At atmospheric conditions, the mass transfer coefficient in the gas phase $k_{\mathrm{G}}$ is two to three orders of magnitude larger than the mass transfer coefficient in the liquid phase $k_{\mathrm{L}}$. Taking into account the inverse proportionality between $k_{\mathrm{G}}$ and $\sqrt{P}$, as found by Versteeg et al. [14], gas phase resistance accounts for less than $10 \%$ of the total resistance to mass transfer at $2.0 \mathrm{MPa}$ and is therefore neglected. Thus, all the criteria for application of Eq. (11) are met and the interfacial area can be calculated directly from the absorption rate measurements.

For each absorption experiment, the following concentrations are determined: $\mathrm{CO}_{2}$ concentrations in the gas in- and outlet flows as well as the DEA concentration and $\mathrm{CO}_{2}$-liquid load in each fresh or regenerated batch of DEA solution.

The absorption rate is calculated from

$\phi_{\mathrm{CO}_{2}}=\phi_{\mathrm{v}}\left(c_{\mathrm{CO}_{2}, \mathrm{G}, \text { in }}-c_{\mathrm{CO}_{2}, \mathrm{G}, \mathrm{out}}\right)$

\section{Results}

\subsection{Visual and Photographic Observations}

In order to make preliminary qualitative assessment of the reactor's performance at elevated pressures, several photographs were taken of a nitrogen in water dispersion, at different pressures. A sintered plate was used as gas distributor in these experiments. Some photographs are presented in Figs 2, 3 and 4. Fig. 2 shows photographs at three different stirring speeds of $N=11.7$, 15 and $25 \mathrm{rps}$, at constant pressure of $P=0.1 \mathrm{MPa}$ and constant superficial gas velocity of $v_{\mathrm{G}}=0.5 \mathrm{~cm} / \mathrm{s}$. The gas hold-up clearly increases with increasing stirring speed. The critical stirring speed $N_{0}$ for a fully developed dispersion, see Westerterp et al. [30], is between 11.7 and 15 rps. Figs 3 and 4 show photographs of the dispersion at the same stirring speeds and superficial gas velocities but two different pressures, i.e. $P=0.6$ and $1.1 \mathrm{MPa}$. Both sets show an increase in the gas hold-up with increasing stirring speed; the critical speed $N_{0}$ again lies between 11.7 and 15 rps.

At constant stirring speed, an increase in the gas hold-up with increasing pressure is observed. This is in contrast to the findings of Vafopoulos et al. [5] who, on taking photographs, found no in-

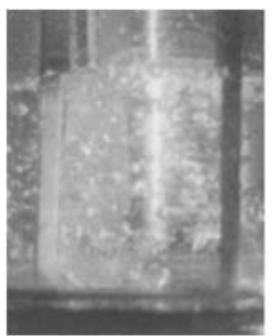

$N=11.7 \mathrm{~s}^{-1}$

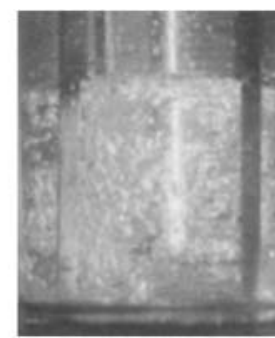

$N=15.0 \mathrm{~s}^{-1}$

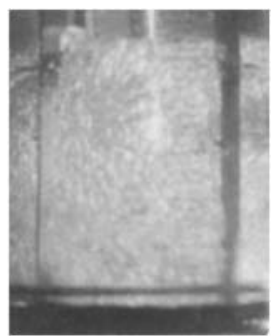

$N=25.0 \mathrm{~s}^{-1}$

Fig. 2. Photographs taken at $P=0.1 \mathrm{MPa}$ and $v_{\mathrm{g}}=0.50 \mathrm{~cm} / \mathrm{s}$.

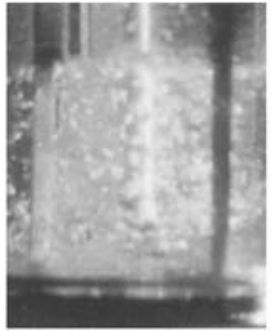

$N=11.7 \mathrm{~s}^{-1}$

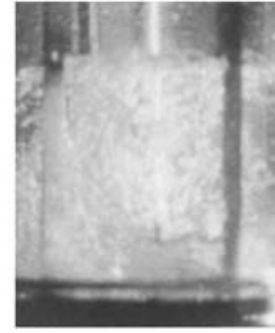

$N=15.0 \mathrm{~s}^{-1}$

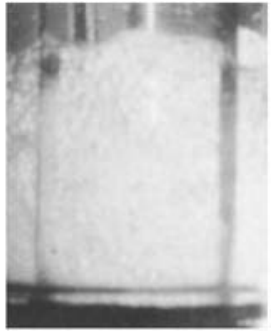

$N=25.0 \mathrm{~s}^{-1}$

Fig. 3. Photographs taken at $P=0.6 \mathrm{MPa}$ and $v_{\mathrm{g}}=0.50 \mathrm{~cm} / \mathrm{s}$.

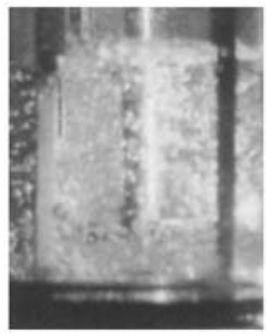

$$
N=11.7 \mathrm{~s}^{-1}
$$

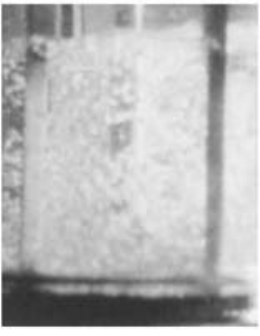

$N=15.0 \mathrm{~s}^{-1}$

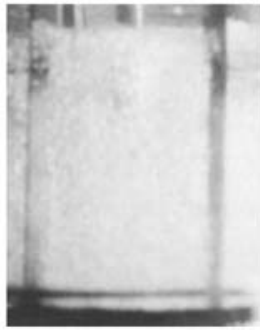

$N=25.0 \mathrm{~s}^{-1}$
Fig. 4. Photographs taken at $P=1.1 \mathrm{MPa}$ and $v_{\mathrm{g}}=0.50 \mathrm{~cm} / \mathrm{s}$. 
fluence of pressure in the range from 0.1 to $1 \mathrm{MPa}$ for an air-water system, in a mechanically agitated transparent reactor with $T=$ $0.44 \mathrm{~m}, D_{\mathrm{i}} / T=0.33$ and $H / T=1$ at $v_{\mathrm{G}}=0.22-1.75 \mathrm{~cm} / \mathrm{s}$.

It should be borne in mind (see Joshi et al. [31] and Charpentier [32]) that the photographic technique is subject to serious limitations and only gives local values of bubble diameters and interfacial areas at the wall.

\subsection{Evaluation of Chemical Absorption Experiments}

In order to determine the interfacial area from an absorption measurement, the liquid phase is assumed to be completely mixed. The DEA concentration is corrected for the $\mathrm{CO}_{2}$ load in liquid feed and the amount of $\mathrm{CO}_{2}$ absorbed. The absorption rate constant is then calculated from Eq. (12) and interfacial areas found by combination of Eqs (11) and (16) to

$$
a=\frac{\phi_{\mathrm{v}}\left(c_{\mathrm{CO}_{2}, \mathrm{G}, \mathrm{in}}-c_{\mathrm{CO}_{2}, \mathrm{G}, \text { out }}\right)}{m V_{\mathrm{L}} \sqrt{k_{1, \mathrm{p}}\left(\bar{c}_{\mathrm{DEA}, \mathrm{L}}\right)^{p} D_{\mathrm{CO}_{2}}} \Delta c_{\mathrm{CO}_{2}, \mathrm{G}}} .
$$

Here, $\Delta c_{\mathrm{CO}_{2}, \mathrm{G}}$ is the average driving force for mass transfer. If the residence time distribution (RTD) of the gas phase is equivalent to that of a continuous stirred tank reactor (CSTR), then $\Delta c_{\mathrm{CO}_{2}, \mathrm{G}}$ is equal to the $\mathrm{CO}_{2}$ concentration in the gas outlet:

$\Delta c_{\mathrm{CO}_{2}, \mathrm{G}}=c_{\mathrm{CO}_{2}, \mathrm{G}, \text { out }}$

For an RTD of the gas phase equivalent to that of a plug flow reactor (PFR), $\Delta c_{\mathrm{CO}_{2}, \mathrm{G}}$ is equal to the logarithmic mean difference in the reactor

$\Delta c_{\mathrm{CO}_{2}, \mathrm{G}}=\frac{\left(c_{\mathrm{CO}_{2}, \mathrm{G}, \text { in }}-c_{\mathrm{CO}_{2}, \mathrm{G}, \text { out }}\right)}{\ln \left(c_{\mathrm{CO}_{2}, \mathrm{G}, \text { in }} / c_{\mathrm{CO}_{2}, \mathrm{G}, \text { out }}\right)}$.

The relatively high solubility of $\mathrm{CO}_{2}$ can produce high $\mathrm{CO}_{2}$ conversions in the gas phase. From Eqs (17) to (19) it can be seen that:

a) large differences between the calculated mass transfer parameters are obtained for the two extreme gas phase RTD's.

b) large errors in the calculated mass transfer parameters are obtained even for a small deviation from an assumed mixing behaviour of the gas phase.

Despite extensive research over many years, on mechanically agitated gas-liquid reactors, only limited data are available on the RTD in the gas phase. The studies of Hanhart et al. [33] and of Gal-Or and Resnick [34] indicate that, above the critical stirring speed $N_{0}$, the RTD in the gas phase lies between that of one ideal CSTR and a cascade of two such reactors. Mehta and Sharma [24] observed in their experiments with different $\mathrm{CO}_{2}$-amine systems that the gas phase was completely mixed at stirring speeds in excess of the critical speed $N_{0}$. Hassan and Robinson [35] confirmed that, for all practical purposes, in the case of coalescencing systems and gas phase conversions below $80 \%$, the gas phase can be considered as completely mixed.
In a series of absorption experiments at different $\mathrm{CO}_{2}$ conversions $(40-99 \%)$, the sensitivity of the present interfacial area determinations towards $\mathrm{CO}_{2}$ conversion in the gas phase was examined for the two extreme RTD's. Experiments were carried out with a sintered gas distributor at four superficial gas velocities, i.e. $v_{\mathrm{g}}=0.25,0.50,0.75$ and $1.00 \mathrm{~cm} / \mathrm{s}$, respectively, and at three stirring speeds of $N=8.3,16.7$ and 25 rps. These experiments were carried out at seven pressures of $P=0.11,0.2,0.3$, $0.5,0.7,0.9$ and $1.1 \mathrm{MPa}$, respectively.

Interfacial areas measured at $P=0.3 \mathrm{MPa}$ are plotted versus stirring speed in Figs 5 and 6 , for RTD's in the gas phase corresponding to those of a CSTR and a PFR. The experimental data are given in Table 2.

Evaluation of these experiments under the assumption of a completely mixed gas phase at the two lowest gas velocities and the

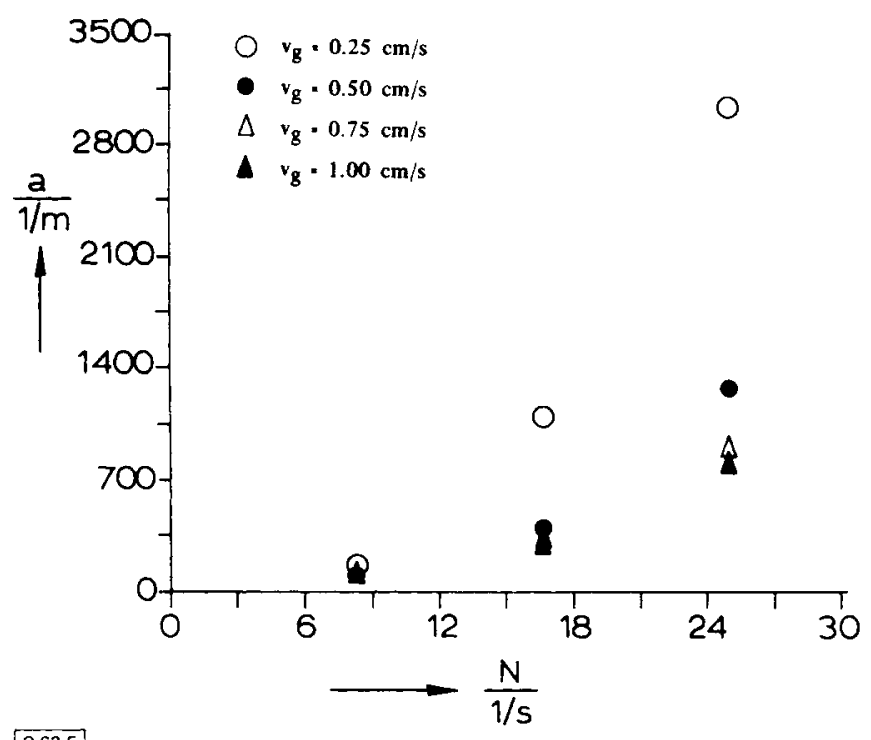

Fig. 5. Interfacial area vs stirring speed at $P=0.3 \mathrm{MPa}$ (CSTR).

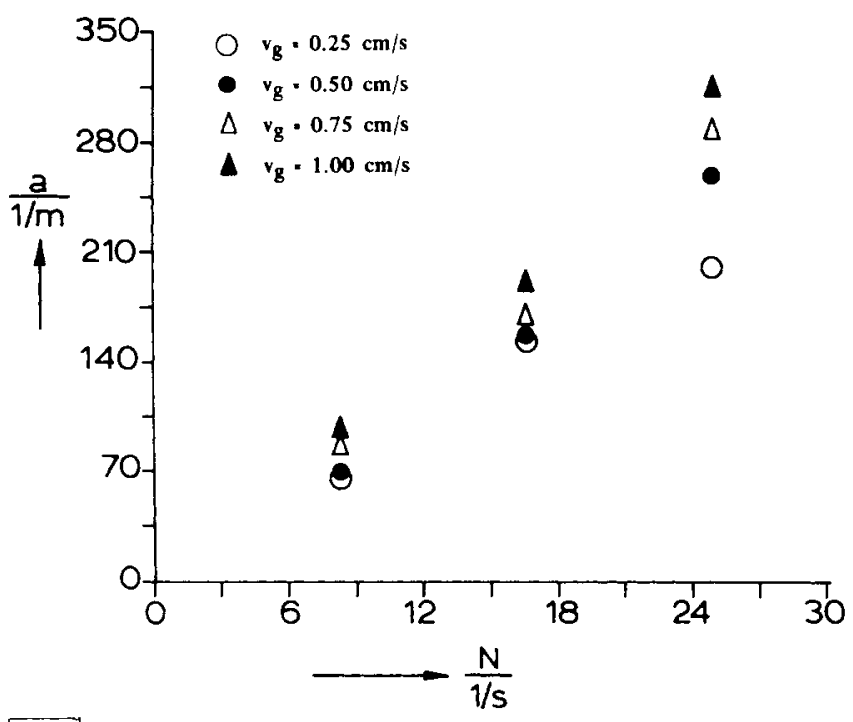

C 63.6

Fig. 6. Interfacial area vs stirring speed at $P=0.3 \mathrm{MPa}$ (PFR). 
Table 2. Experimental Data from Absorption Experiments at $P=0.3 \mathrm{MPa}$ and $[D E A]=0.79 \mathrm{~mol} / \mathrm{kg}$.

\begin{tabular}{llllcc}
$\begin{array}{l}v_{\mathrm{g}} \\
{[\mathrm{cm} / \mathrm{s}]}\end{array}$ & \multicolumn{1}{c}{$N$} & $\begin{array}{l}y_{\mathrm{CO}_{2}, \text { in }} \\
{[-]}\end{array}$ & $\begin{array}{l}\xi_{\mathrm{CO}_{2}} \\
{[\%]}\end{array}$ & $\begin{array}{l}a \text { (mixed) } \\
{\left[\mathrm{m}^{-1}\right]}\end{array}$ & $\begin{array}{l}a \text { (plug flow) } \\
{\left[\mathrm{m}^{-1}\right]}\end{array}$ \\
\hline 0.25 & 500 & 0.0210 & 74 & 139 & 65 \\
0.25 & 1000 & 0.0210 & 96 & 1097 & 153 \\
0.25 & 1500 & 0.0210 & 99 & 3027 & 200 \\
0.50 & 500 & 0.0195 & 51 & 101 & 69 \\
0.50 & 1000 & 0.0195 & 79 & 383 & 155 \\
0.50 & 1500 & 0.0195 & 93 & 1263 & 257 \\
0.75 & 500 & 0.0198 & 44 & 115 & 85 \\
0.75 & 1000 & 0.0198 & 68 & 317 & 169 \\
0.75 & 1500 & 0.0198 & 86 & 890 & 278 \\
1.00 & 500 & 0.0198 & 39 & 127 & 98 \\
1.00 & 1000 & 0.0198 & 62 & 321 & 190 \\
1.00 & 1500 & 0.0198 & 80 & 782 & 313 \\
\hline
\end{tabular}

highest stirring speeds results in extremely large values for the interfacial areas. This is attributed to very high $\mathrm{CO}_{2}$ conversions in the gas phase, i.e. in excess of $90 \%$. Assumption of plug flow behaviour for the gas phase results in an increase of interfacial area with increasing gas velocities and stirring speeds. The deviation of the interfacial area at $v_{\mathrm{g}}=0.25 \mathrm{~cm} / \mathrm{s}$ and $N=25 \mathrm{rps}$, shown in Fig. 6, suggests a partial depletion of the gas bubbles.

Westerterp et al. [29] showed that, for $N<N_{0}$, the interfacial area is scarcely affected by agitation and depends only on the superficial gas velocity whilst, for $N>N_{0}$, the interfacial area varies directly with stirring speed and is not affected by superficial gas velocity. This was confirmed by Mehta and Sharma [24] and by van Dierendonck [36] and, for $N<N_{0}$, by Sridhar and Potter [11]. Sridhar and Potter [11] observed that, only at $N>N_{0}$, the interfacial area and gas hold-up are affected by the superficial gas velocity.

Based on these literature data and on experimental results, it was established that, for $N>N_{0}$ and $\mathrm{CO}_{2}$ gas phase conversions below $80 \%$, interfacial areas can be calculated accurately on the assumption of a completely mixed gas phase. For $N<N_{0}$ and $\mathrm{CO}_{2}$ gas phase conversions below $40 \%$, the assumption of a completely mixed gas phase also results in fairly accurate values of interfacial area.

\subsection{Interfacial Areas}

These conditions lead to an experimental restriction in the use of superficial gas velocities of $v_{\mathrm{g}}=0.50,0.75$ and $1.00 \mathrm{~cm} / \mathrm{s}$ or higher, at stirring speeds of $N=11.7,16.7$ and 25 rps respectively. In the following, only experiments, performed at superficial gas velocities in excess of the minimum permissible ones, are presented. The interfacial areas are calculated on the basis of a completely mixed gas phase.

The interfacial areas measured at $v_{\mathrm{g}}=1.00 \mathrm{~cm} / \mathrm{s}$ are plotted versus the reactor pressure in Fig. 7: there is no evidence that pressure exerts any influence at all. The interfacial areas measured at $v_{\mathrm{g}}=0.50 \mathrm{~cm} / \mathrm{s}$ and $N=11.7 \mathrm{rps}$ as well as at $v_{\mathrm{g}}=0.75 \mathrm{~cm} / \mathrm{s}$ and $N=11.7$ or 16.7 rps do not show any influence of the reactor pressure either.

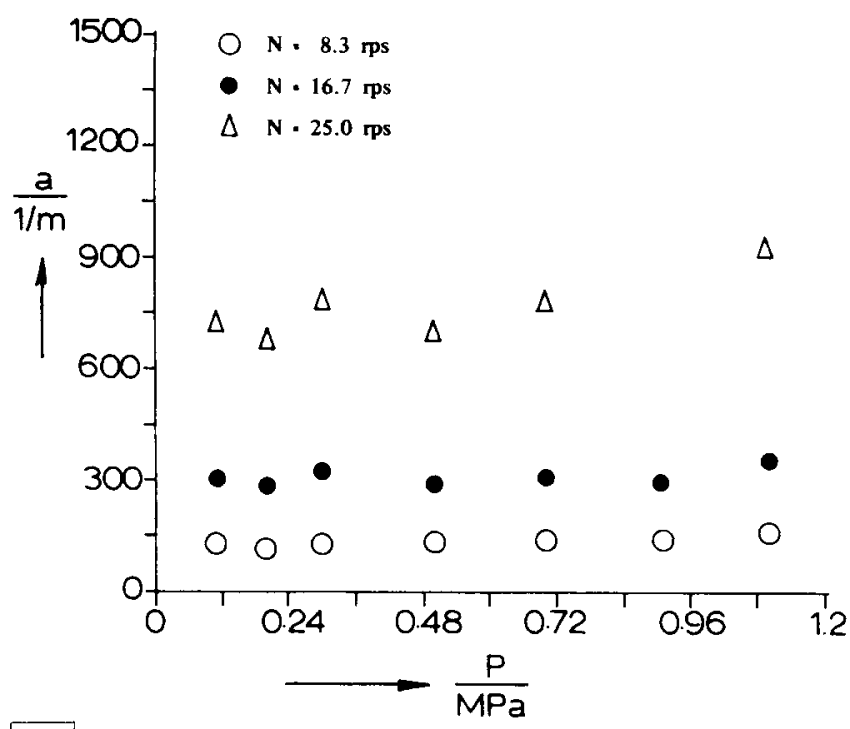

Fig. 7. Interfacial area vs reactor pressure at $v_{\mathrm{g}}=1.00 \mathrm{~cm} / \mathrm{s}(\mathrm{CSTR})$.

At stirring speed of $N=16.7 \mathrm{rps}$, i.e. above the critical speed $N_{0}$, an additional series of experiments was carried out with a single orifice as the gas inlet. Interfacial areas were measured at three superficial gas velocities of $v_{\mathrm{g}}=1.00,1.50$ and $2.00 \mathrm{~cm} / \mathrm{s}$ respectively and seven pressures of up to $1.7 \mathrm{MPa}$. The results are plotted in Fig. 8 and, again, the influence of operating pressure is insignificant. The accuracy of the individual determinations is $\pm 5 \%$. No distinction can be made between interfacial areas for the three superficial gas velocities on account of accuracy and the fact that $v_{\mathrm{g}}$ has little influence on interfacial areas at $N=16.7$ rps which is just above $N_{0}$.

Again, no influence of pressure on interfacial areas was observed in any of the present experiments. This is in contrast to the findings of Sridhar and Potter [11] who used a light transmission probe to determine the interfacial areas. They report increases in interfacial areas of as much as $75 \%$ for a pressure increase of up to $1.1 \mathrm{MPa}$.

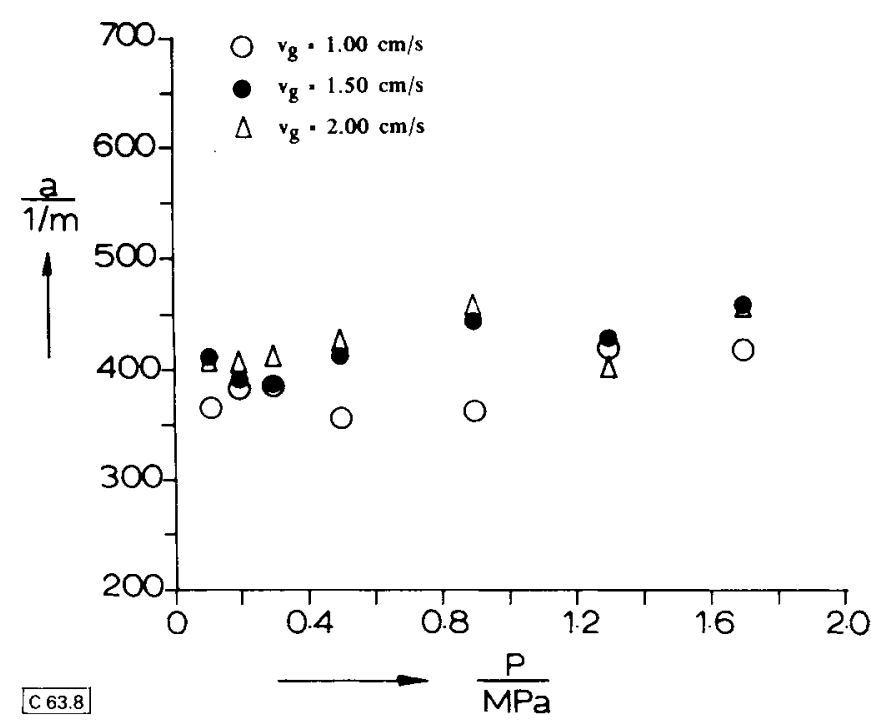

Fig. 8. Interfacial area vs reactor pressure at $N=16.7$ rps (CSTR). 


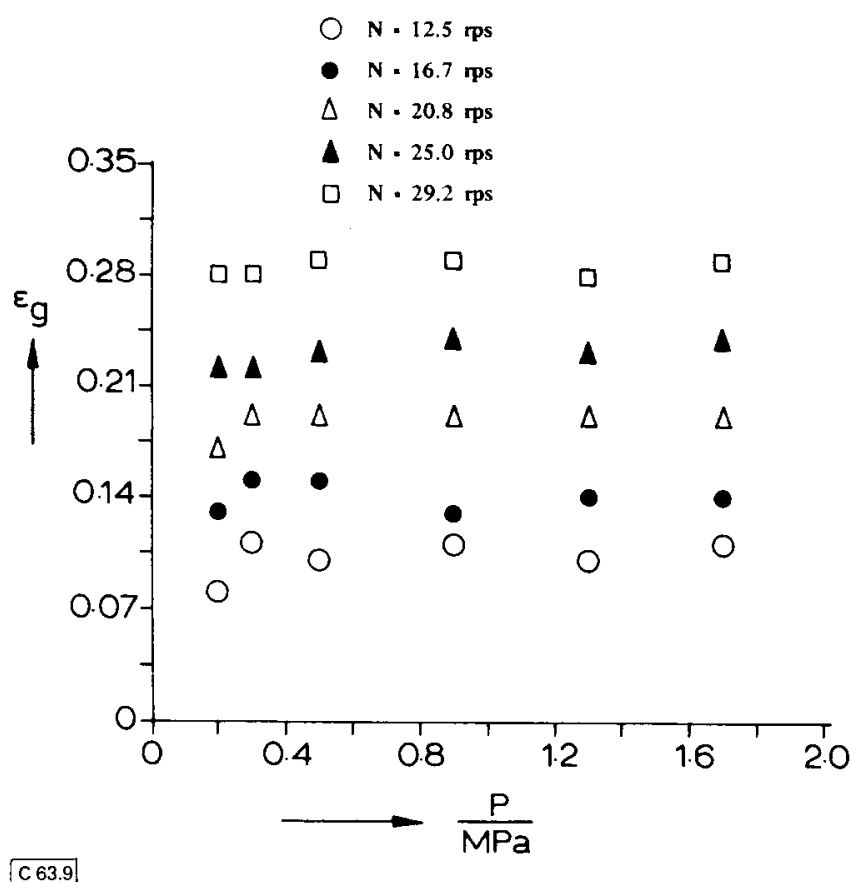

Fig. 9. Gas hold-up vs reactor pressure at $v_{\mathrm{g}}=2.00 \mathrm{~cm} / \mathrm{s}$ in water.

\subsection{Gas Hold-up}

The absorption experiments are laborious and time consuming. Additional gas hold-up measurements were carried out in order to obtain a rough assessment of the influence of operating pressure on the gas hold-up. The gas hold-ups were determined by measuring the difference in height between the gassed and non-gassed dispersion levels. The surface is severely disturbed at stirring speeds below $N=10 \mathrm{rps}$ by irregular outbursts of large

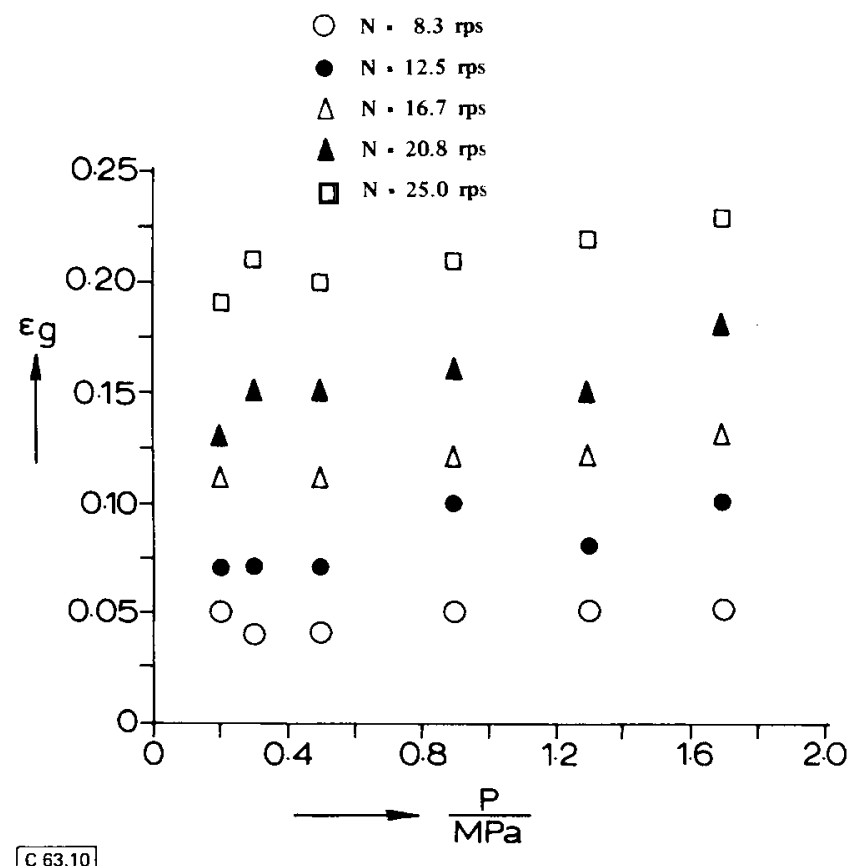

Fig. 10. Gas hold-up vs reactor pressure at $v_{\mathrm{g}}=2.00 \mathrm{~cm} / \mathrm{s}$ in converted DEA solution. bubbles and at speeds above $N=25 \mathrm{rps}$ by the high shear forces. This leads to accuracies in the measurements of circa $\pm 10 \%$, while the most accurate values are obtained at intermediate stirring speeds. An aqueous DEA solution with a similar composition to that used in the absorption experiments, a fresh unconverted DEA solution as well as water are sparged with nitrogen. Two superficial gas velocities of $v_{\mathrm{g}}=1.00$ and $2.00 \mathrm{~cm} / \mathrm{s}$ are used over a wide range of stirring speeds from $N=4.2$ to $29.2 \mathrm{rps}$. The fresh DEA solution foamed at higher stirring speeds.

For $v_{\mathrm{g}}=2.00 \mathrm{~cm} / \mathrm{s}$ the results are plotted in Figs 9, 10 and 11: again, no marked influence of pressure on gas hold-up is observed.

These results are in contradiction to photographic observations from Figs 2, 3 and 4; they stress the care which should be taken in interpreting visual or photographic observations. They also contradict the results of Sridhar and Potter [10], who determined gas hold-ups in their reactor by the manometric method and found a clear indication of pressure influence, see discussion.

The two non-foaming systems are compared in Fig. 12 for both superficial gas velocities: the gas hold-ups in the DEA solution are lower than those in water.

\section{Discussion and Conclusions}

The contradictory conclusions from own photographic observations and interfacial area and gas hold-up determinations demonstrate once again the uncertainty of photographic or visual measurements through the wall of the reactor. The local values at the wall are not necessarily representative of the overall values of interfacial areas in the reactor.

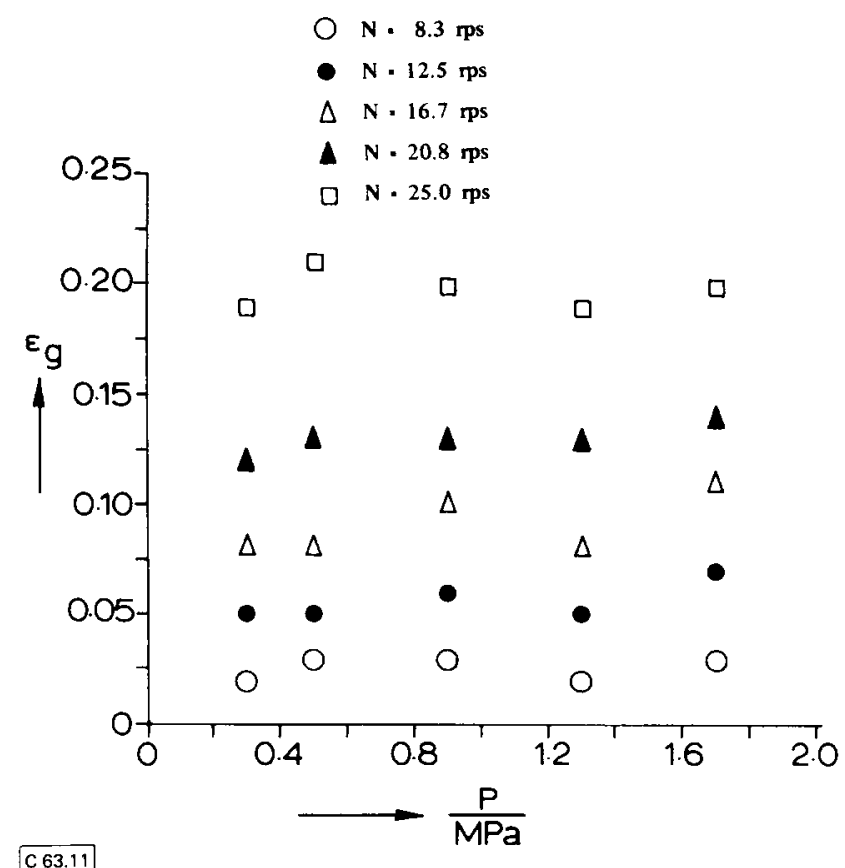

Fig. 11. Gas hold-up vs reactor pressure at $v_{\mathrm{g}}=2.00 \mathrm{~cm} / \mathrm{s}$ in fresh DEA solution. 


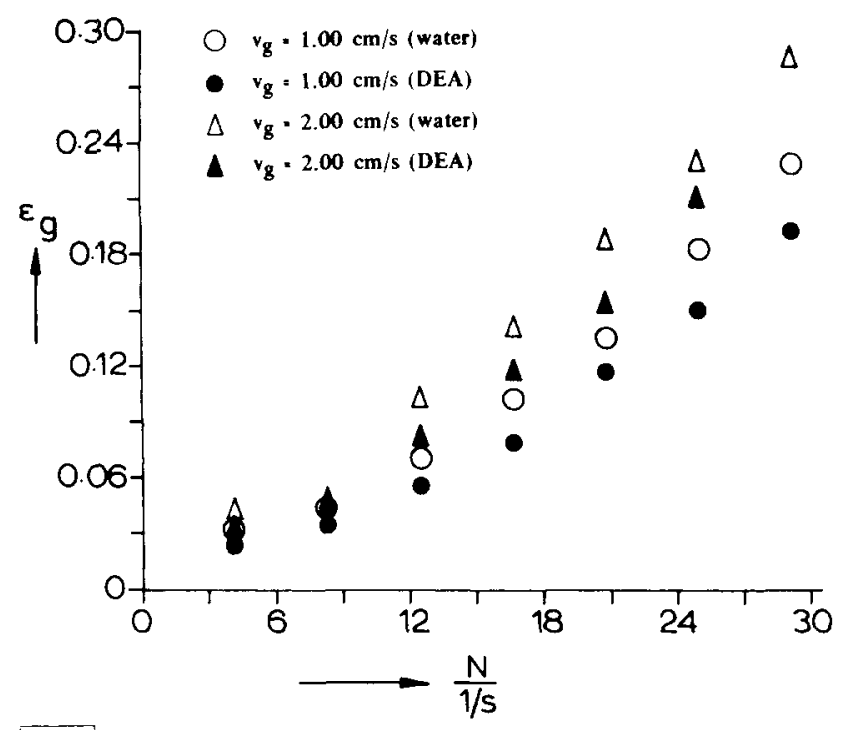

C63.12

Fig. 12. Mean gas hold-up vs stirring speed in water and in converted DEA solution.

Sridhar and Potter [11, 37] used a light transmission probe and determined, at about 40 locations inside the reactor, interfacial areas which were averaged to obtain an overall value for the whole reactor. Their probe, consisting of stainless steel tubes, 5 $\mathrm{mm}$ in diameter, is larger than the average bubble diameter of 3 $\mathrm{mm}$ : in the authors' opinion, this may produce serious disturbances in the hydrodynamic conditions in the reactor and at the sampling point. Although Sridhar and Potter [11] presented some values of interfacial areas in the proximity of the impeller, probably they were unable to determine those in the immediate vicinity of the impeller where the smallest bubbles occur. These two aspects indicate that the results of Sridhar and Potter $[11,37] \mathrm{de}-$ pend on experimental technique and do not represent the true interfacial areas.

Using the manometric method, Sridhar and Potter [10] also determined an increase in the gas hold-up with increasing reactor pressure. They corrected their measurements for the dynamic pressure difference resulting from the radial and tangential flow of the liquid. In the authors' experience, this dynamic pressure difference is very sensitive to the location of sampling points and leads to considerable errors, especially in small mechanically agitated reactors. The determination of the gas hold-up on the basis of height differences can also lead to errors, especially at low stirring speeds and in foaming systems. For this reason, more gas hold-up measurements in different gas-liquid systems should be performed, aiming at an explanation of the difference between own results and those of Sridhar and Potter [10]. It is obvious that the fact of gas hold-ups being independent of pressure supports the results of interfacial area determinations.

The use of Eq. (18) is restricted to a micromixed gas phase. In the mechanically agitated reactor, the gas phase is subject to finite coalescence and redispersion rates and bubble diameters are not uniform. If the absorption process is of first order with respect to the component being absorbed from the gas phase, which is the case for own $\mathrm{CO}_{2}$ system, Eq. (18) can also be applied to a com- pletely segregated gas phase with a uniform bubble diameter, see Hanhart et al. [33]. Compared to a bubble column, the bubble diameter distribution in the mechanically agitated reactor is rather narrow but still not uniform. This means that, for higher $\mathrm{CO}_{2}$ conversions, bubble size distribution, as explained by Midoux et al. [38] and Schumpe and Deckwer [39], should also be taken into account.

Based on the scarce literature results on the RTD of the gas phase together with the characteristic behaviour of the reactor and own experiments, it may be concluded that, as a rule, at stirring speeds in excess of the critical speed $N_{0}$, the gas phase is completely mixed. Furthermore, it may be concluded that, in order to calculate realistic values, the $\mathrm{CO}_{2}$ conversion in the gas phase must remain below $80 \%$. The first conclusion agrees with the findings of Mehta and Sharma [24] and both agree with those of Hassan and Robinson [35]. Therefore, the interfacial areas, calculated from own experiments, appear realistic and accurate.

In a small mechanically agitated reactor, no influence of operating pressures up to $1.7 \mathrm{MPa}$ on the interfacial areas in an aqueous DEA solution was observed. In this system and in water, no influence on the gas hold-up was found in this pressure range either. Before a general conclusion can be drawn, regarding the influence of operating pressure on the mass transfer parameters in a mechanically agitated gas-liquid reactor, more experimental work in larger vessels is required. The present study indicates that the correlations for mass transfer parameters, based on the experiments at atmospheric pressures, can also be applied to high pressure mechanically agitated gas-liquid reactors.

\section{Acknowledgements}

The investigations were supported by the Netherlands Foundation for Chemical Research (SON) and the Netherlands Organization for the Advancement of Pure Research (ZWO).

\section{Received: May 8, 1987 [CET63]}

\section{Symbols used}

$\begin{array}{ll}a & {\left[\mathrm{~m}^{-1}\right]} \\ \mathrm{Al} & {[-]} \\ c & {\left[\mathrm{~mol} / \mathrm{m}^{3}\right]} \\ \bar{c} & {\left[\mathrm{~mol} / \mathrm{m}^{3}\right]} \\ \Delta c & {\left[\mathrm{~mol} / \mathrm{m}^{3}\right]} \\ d_{\mathrm{i}} & {[\mathrm{m}]} \\ \bar{d}_{\mathrm{p}} & {[\mathrm{m}]} \\ D & {\left[\mathrm{~m}^{2} \mathrm{~s}\right]} \\ D_{\mathrm{i}} & {[\mathrm{m}]} \\ E & {[-]} \\ E_{\mathrm{t}} & {[\mathrm{W}]} \\ h & {[\mathrm{~m}]} \\ H & {[\mathrm{~m}]} \\ \mathrm{Ha} & {[-]} \\ J & {\left[\mathrm{~mol} / \mathrm{m}^{2} \mathrm{~s}\right]} \\ k & {[\mathrm{~m} / \mathrm{s}]} \\ k_{\text {ov }} & {[1 / \mathrm{s}]} \\ k_{\mathrm{n}, \mathrm{p}} & {\left[\mathrm{m}^{3(\mathrm{p}+\mathrm{n}-1)} / \mathrm{mol}^{(\mathrm{p}+\mathrm{n}-1} \mathrm{s}\right]}\end{array}$

interfacial area

Hinterland coefficient, Eq. (3) concentration bulk concentration driving force for mass transfer gas inlet diameter mean pore diameter diffusivity impeller diameter enhancement factor, Eq. (5) total energy impeller height dispersion height Hatta number, Eq. (6) molar flux mass transfer coefficient overall reaction rate constant

$k_{\mathrm{n}, \mathrm{p}} \quad\left[\mathrm{m}^{3(\mathrm{p}+\mathrm{n}-1)} / \mathrm{mol}^{(\mathrm{p}+\mathrm{n}-1} \mathrm{s}\right] \quad$ rate constant for reaction of order $(n, p)$ 


$\begin{array}{lll}m & {[-]} & \text { distribution coefficient, } c_{\mathrm{L}}=m c_{\mathrm{g}} \\ N & {[1 / \mathrm{s}]} & \text { stirring speed } \\ N_{0} & {[1 / \mathrm{s}]} & \text { critical stirring speed } \\ P & {[\mathrm{~Pa}]} & \text { pressure } \\ P_{\mathrm{g}} & {[\mathrm{W}]} & \text { power input } \\ T & {[\mathrm{~m}]} & \text { tank diameter } \\ v_{\mathrm{g}} & {[\mathrm{m} / \mathrm{s}]} & \text { superficial gas velocity } \\ V & {\left[\mathrm{~m}^{3}\right]} & \text { volume } \\ W & {[\mathrm{~m}]} & \text { baffle width } \\ y & {[-]} & \text { molar fraction in the gas phase } \\ \varepsilon_{\mathrm{g}} & {[-]} & \text { gas hold-up } \\ \zeta & {[-]} & \text { gas phase conversion } \\ \mu_{\mathrm{L}} & {\left[\mathrm{N} \mathrm{s} / \mathrm{m}^{2}\right]} & \text { liquid viscosity } \\ \varrho_{\mathrm{L}} & {\left[\mathrm{kg} / \mathrm{m}^{3}\right]} & \text { liquid density } \\ \sigma & {[\mathrm{N} / \mathrm{m}]} & \text { surface tension } \\ \phi & {\left[\mathrm{mol} / \mathrm{s} ; \mathrm{kg} / \mathrm{s} ; \mathrm{m}^{3} / \mathrm{s}\right]} & \text { flow rate }\end{array}$

\section{Subscripts}

$\begin{array}{ll}\text { A } & \text { gas phase component } \\ \text { B } & \text { liquid phase component } \\ \text { G } & \text { gas phase } \\ \text { i } & \text { interface } \\ \text { in } & \text { inlet } \\ \text { L } & \text { liquid phase } \\ \text { m } & \text { mass flow } \\ \text { out } & \text { outlet } \\ \text { R } & \text { reactor } \\ \text { v } & \text { volumetric flow }\end{array}$

\section{References}

[1] Tarmy, B., Chang, M., Coulaloglou, C., Ponzi, P., Chem. Eng 87. Oct. (1984) p. 18.

[2] Pijls, N.J.M., Teurlings, A., Thoenes, D., private communication, Eindhoven University, The Netherlands 1985.

[3] Idogawa, K., Ikeda, K., Fukuda, T., Morooka, S., Kagaku Kogaku Ronbunshu 11 (1985) p. 253.

[4] Idogawa, K., Ikeda, K., Fukuda, T., Morooka, S., Kagaku Kogaku Ronbushu II (1985) p. 433.

[5] Vafopoulos, I., Sztatescny, K., Moser, F., Chem.-Ing.-Tech. 47 (1975) p. 681.

[6] Deckwer, W.D., Louisi, Y., Zaidi, A., Ralek, M., Ind. Eng Chem. Process Des. Dev. 19 (1980) p. 699.

[7] Kölbel, H., Borchers, E., Langemann, H., Chem.-Ing.-Tech. 33 (1961) p. 668.
[8] Albal, R.S., Shah, Y.T., Carr, N.L., Bell, A.T., Chem. Eng Sci. 39 (1984) p. 905.

[9] Albal, R.S., Shah, Y.T., Schumpe, A., Carr, N.L., Chem. Eng J. (Loughborough, Engl.) 27(1983) p. 61.

[10] Sridhar, T., Potter, O.E., Ind. Eng Chem. Fundam. 19 (1980) p. 21.

[11] Sridhar, T., Potter, O.E., Chem. Eng Sci. 35 (1980) p. 683.

[12] LaNauze, R.D., Harris, I.J., Trans. Inst. Chem. Eng. 52 (1974) p. 337.

[13] Idogawa, K., Ikeda, K., Fukuda, T., Morooka, S., Kagaku Kogaku Ronbunshu 12 (1986) p. 107.

[14] Versteeg, G.F., Blauwhoff, P.P.M., van Swaaij, W.P.M., to be published Chem. Eng Sci. 1987.

[15] Teramoto, M., Tai, S., Nishii, K., Teranishi, H., Chem. Eng J. 8 (1974) p. 223.

[16] Deimling, A., Karandikar, B.M., Shah, Y.T., Carr, N.L., Chem. Eng J. 29 (1984) p. 127.

[17] Calderbank, P.H., Trans. Inst. Chem. Eng. 36 (1958) p.443.

[18] Sharma, M.M., Danckwerts, P.V., Brit. Chem. Eng 15 (1970) p. 522.

[19] Westerterp, K.R., van Swaaij, W.P.M., Beenackers, A.A.C.M., Chemical Reaction Design and Operation, John Wiley \& Sons, New York 1984.

[20] Linek, V., Vacek, V., Chem. Eng Sci. 36 (1981) p. 1747.

[21] Bartos, T.M., Satterfield, C.N., AIChE J. 32 (1986) p. 773.

[22] Danckwerts, P.V., Sharma, M.M., Chem. Eng (N.Y.) Oct. (1966) p. 244.

[23] Shridaran, K., Sharma, M.M., Chem. Eng Sci. 31 (1976) p. 767.

[24] Mehta, V.D., Sharma, M.M., Chem. Eng Sci. 26 (1971) p. 461.

[25] Midoux, N., Morsi, B.I., Purwasasmita, M., Laurent, A., Charpentier, J.C., Chem. Eng Sci. 39 (1984) p. 781.

[26] Versteeg, C.F., Thesis, Univ. Twente, The Netherlands 1987.

[27] Blauwhoff, P.M.M., Versteeg, C.F., van Swaaij, W.P.M., Chem. Eng Sci. 39 (1984) p. 207.

[28] Versteeg, G.F., van Swaaij, W.P.M., to be published in Chem. Eng Sci. 1987.

[29] Versteeg, G.F., Kuipers, J.A.M., van Beckum, F.P.H., van Swaaij, W.P.M., to be published in Chem. Eng Sci. 1987.

[30] Westerterp, K.R., van Dierendonck, L.L., Dekraa, J., Chem. Eng Sci. 18 (1963) p. 157

[31] Joshi, J.B., Pandit, A.B., Sharma, M.M., Chem. Eng Sci. 27 (1982) p. 813.

[32] Charpentier, J.C., Adv. Chem. Eng $I 1$ (1981) p. 1.

[33] Hanhart, J., Kramers, H., Westerterp, K.R., Chem. Eng Sci. 18(1963) p. 503.

[34] Gal-Or, B., Resnick, W., Ind. Eng Chem. Process Des. Dev. 5 (1966) p. 15.

[35] Hassan, I.T.M., Robinson, C.W., Chem. Eng Sci. 35 (1980) p. 1277.

[36] van Dierendonck, L.L., Thesis, Univ. Twente, The Netherlands 1970.

[37] Sridhar, T., Potter, O.E., Chem. Eng Sci. 33 (1978) p. 1347.

[38] Midoux, N., Laurent, A., Charpentier, J.C., AIChE J. 26 (1980) p. 157.

[39] Schumpe, A., Deckwer, W.D., Chem. Eng Sci. 35 (1980) p. 2221. 